\title{
Some Trinitroazetidine Isomers - A DFT Treatment
}

\section{Lemi Türker}

Department of Chemistry, Middle East Technical University, Üniversiteler, Eskişehir Yolu No: 1, 06800 Çankaya/Ankara, Turkey; e-mail: 1turker@gmail.com; 1turker@metu.edu.tr

\section{Abstract}

The present study considers some trinitroazetidine isomers within the realm of density functional theory $(\mathrm{B} 3 \mathrm{LYP} / 6-311++\mathrm{G}(\mathrm{d}, \mathrm{p}))$. One of the isomers considered is 1,3,3trinitroazetidine (TNAZ) which is the well known insensitive high energy explosive material. Various structural, energetic, quantum chemical and spectral properties of the isomers have been harvested and discussed. Some of the isomers have nitramine bonds and some possess only $\mathrm{C}-\mathrm{NO}_{2}$ bonds. The results indicate that the nitramine moiety somewhat destabilizes the structure electronically but increases the impact insensitivity.

\section{Introduction}

1,3,3-trinitroazetidine (also known as TNAZ) is one of the most widely studied explosives in the recent decades [1-2]. Structurally, it possesses a highly nitrated four membered nitrogen heterocyclic ring (azetidine) having both $\mathrm{C}-\mathrm{NO}_{2}$ and $\mathrm{N}-\mathrm{NO}_{2}$ moieties. It exhibits improved performance as compared to conventional melt castable explosive trinitrotoluene (TNT). It is attributed to the additional energy gained due to the presence of strained ring system [3-8]. For the synthesis of 1,3,3-trinitroazetidine various methods have been reported [9]. TNAZ, being a melt castable high performance explosive has been proposed as potential replacement for TNT [10]. The low melting point of TNAZ $\left(101^{\circ} \mathrm{C}\right)$ enables the processing of formulations on modified production lines. Its performance has been reported as approximately $30 \%$ greater than TNT and it shows excellent thermal stability $\left(>180^{\circ} \mathrm{C}\right)[11]$. Over the known explosives, TNAZ has many

Received: May 4, 2021; Accepted: May 26, 2021

Keywords and phrases: TNAZ, trinitroazetidine, explosive, isomer, DFT.

Copyright (C) 2021 Lemi Türker. This is an open access article distributed under the Creative Commons Attribution License, which permits unrestricted use, distribution, and reproduction in any medium, provided the original work is properly cited. 
added advantages. Such as, it is a highly energetic insensitive material, more powerful than RDX and is less vulnerable than most other nitramines [12,13]. Moreover, TNAZ is soluble in molten TNT (unlike HMX) and is compatible with various materials such as aluminum, steel, brass and glass [14-16]. Recently, some computational studies have been reported on the interaction of pairs of FOX-7 and TNAZ [17] and NTO and TNAZ [18]. In the present study, a density functional (DFT) treatment has been reported on some trinitroazetidine isomers.

\section{Method of Calculation}

In the present study, the initial geometry optimizations of all the structures leading to energy minima were achieved by using MM2 method followed by semi-empirical PM3 self-consistent fields molecular orbital (SCF MO) method $[19,20]$ at the restricted level [21]. Afterwards, the structure optimizations have been managed within the framework of Hartree-Fock (HF) and finally by using density functional theory (DFT) at the level of B3LYP/6-311++G(d,p) (restricted closed-shell) [22,23]. Note that the exchange term of B3LYP consists of hybrid Hartree-Fock and local spin density (LSD) exchange functions with Becke's gradient correlation to LSD exchange [24]. Note that the correlation term of B3LYP consists of the Vosko, Wilk, Nusair (VWN3) local correlation functional [25] and Lee, Yang, Parr (LYP) correlation correction functional [26]. In the present study, the normal mode analysis for each structure yielded no imaginary frequencies for the $3 \mathrm{~N}-$ 6 vibrational degrees of freedom, where $N$ is the number of atoms in the system. This indicates that the structure of each molecule corresponds to at least a local minimum on the potential energy surface. Furthermore, all the bond lengths were thoroughly searched in order to find out whether any bond cleavage occurred or not during the geometry optimization process. All these computations were performed by using SPARTAN 06 [27].

\section{Results and Discussion}

Presently, some isomers of trinitroazetidine is considered in which substituent pattern of TNAZ has been maintained. Namely, two of the three nitro groups possess geminal relationship on the carbon atom of trinitroazetidine. The third nitro group linked either to the nitrogen or carbon atom of the ring (see Figure 1). Consequently, two of the isomers are nitramine type (structures A and B). Structure A stands for TNAZ molecule. 

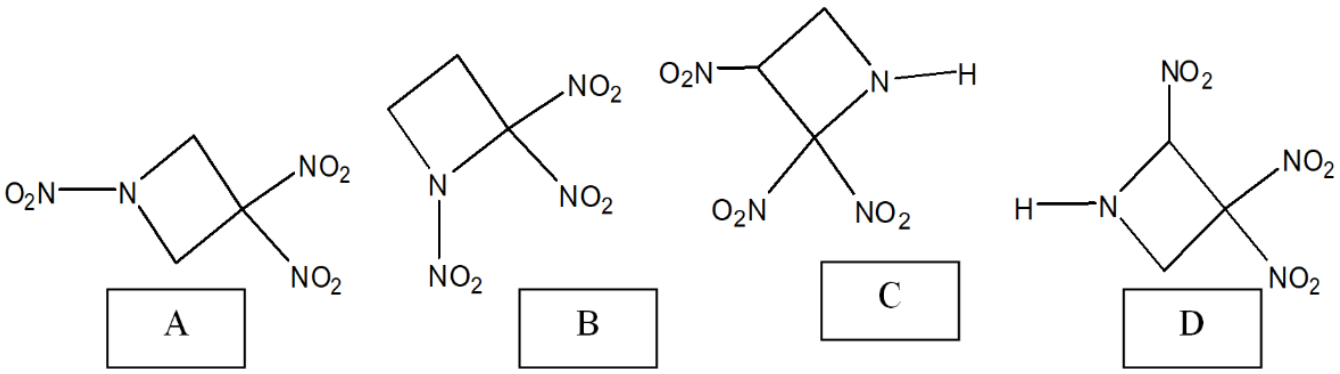

Figure 1. The isomers presently considered.

Figure 2 shows the optimized structures of the isomers considered. The figure also shows the direction of the dipole moment vectors. As seen in the figure the ring is slightly

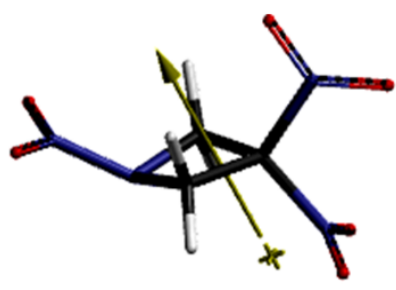

A

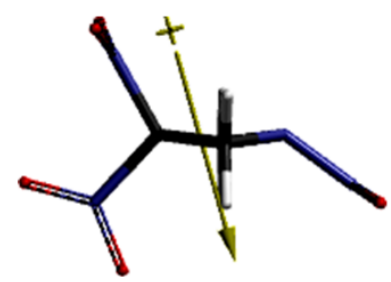

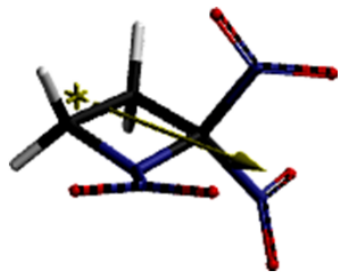

B

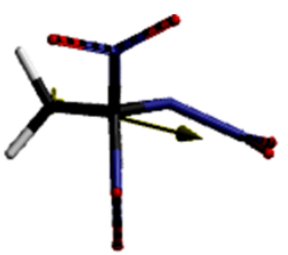

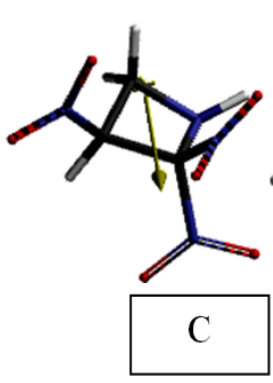
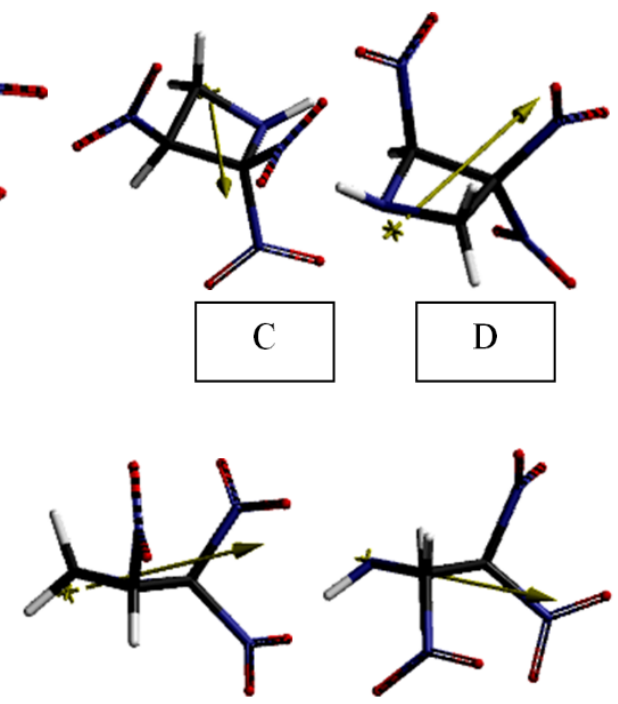

Figure 2. Optimized structures of the isomers considered (From different angles of view).

puckered in all the cases. Table 1 lists some properties of the isomers. All the structures, except the $\log \mathrm{P}$ values and dipole moments, have comparable characteristics. Isomer-B has the highest dipole moment and $\log \mathrm{P}$ values among the set. The position and conformation of the nitro groups dictate the dipole moments and thus the polarity of the structures.

Polarizability (Pol) is defined as [27],

$$
\text { Pol }=0.08 \mathrm{~V}_{\mathrm{VdW}^{-}}-13.0352 \mathrm{H}+0.97992 \mathrm{H}^{2}+41.3791
$$


where $\mathrm{V}_{\mathrm{VdW}}$ is the van der Waals volume, $\mathrm{H}$ is the hardness which is defined as,

$$
\mathrm{H}=-\left(\varepsilon_{\mathrm{HOMO}}-\varepsilon_{\mathrm{LUMO}}\right) / 2
$$

where $\varepsilon_{\mathrm{HOMO}}$ and $\varepsilon_{\mathrm{LUMO}}$ stand for the HOMO and LUMO energies, respectively.

Table 1. Some properties of the isomers.

\begin{tabular}{ccccccc}
\hline Structure & Area $\left(\AA^{\mathbf{2}}\right)$ & $\begin{array}{c}\text { Volume } \\
\left(\AA^{3}\right)\end{array}$ & Ovality & Polarizability & Log P & $\begin{array}{c}\text { Dipole } \\
\text { moment }\end{array}$ \\
\hline A & 173.98 & 139.73 & 1.34 & 51.45 & 1.72 & 0.50 \\
B & 175.70 & 140.23 & 1.35 & 51.45 & 2.34 & 5.93 \\
C & 175.02 & 139.43 & 1.35 & 51.49 & 1.06 & 5.45 \\
D & 173.52 & 139.30 & 1.34 & 51.55 & 1.18 & 4.24 \\
\hline
\end{tabular}

Dipole moments in debye units. Polarizability in $10^{-30} \mathrm{~m}^{3}$.

Table 2 lists the heat of formation values of the isomers. According to the data there, all the isomers are endothermic and follow the order of $B>A>D>C$. Note that both of structures $\mathrm{A}$ and $\mathrm{B}$ are nitramine types. Thus, higher endothermicity of $\mathrm{A}$ and $\mathrm{B}$ over $\mathrm{C}$ and $\mathrm{D}$ could be due to the presence of nitramine structure in the former ones. Whereas the higher endothermicity of B over A (TNAZ) could be attributed to more ring strain present in structure B (see Table 3). In Table 3 internal bond angles of the isomers are tabulated.

Table 2. Heat of formation values of the isomers.

\begin{tabular}{cccc}
\hline $\mathbf{A}$ & B & C & D \\
\hline 117.420 & 134.904 & 96.123 & 101.840 \\
\hline
\end{tabular}

PM3//B3LYP/6-311++G(d,p). Values in degree.

Figure 4 shows the numbering of atoms in the isomers. The sum of internal bond angles could be some sort of indication of the ring strain present. Since, a planar tetragonal structure (like deltoid) possesses that sum of 360 degrees, the sum lesser than 360 degree indicates more puckered thus more strain-relieved ring. Also bond lengths should contribute to the thermo chemistry of the isomers, however in the present case the isomers have very comparable bond lengths. See Figure 3 which shows the calculated bond lengths of the isomers. TNAZ (isomer-A) having a $\mathrm{C}_{2}$ plane of symmetry (comprising the nitramine nitrogen and the geminally nitro-group- substituted carbon 
atom) possesses symmetrically the same ring bond lengths. However, $\mathrm{C}-\mathrm{NO}_{2}$ bonds slightly differ.

Table 3. Internal bond angles (degrees) of the isomers.

\begin{tabular}{llllllll}
\hline \multicolumn{2}{c}{ A } & \multicolumn{2}{c}{ B } & \multicolumn{2}{c}{ C } & \multicolumn{2}{c}{ D } \\
\hline C2N1C4 & 94.11 & C2N1C4 & 95.19 & C1C4C3 & 85.09 & N4C3C4 & 89.01 \\
C2C1C4 & 89.38 & C1C4N1 & 89.16 & C4C3N4 & 91.01 & C1C4C3 & 86.59 \\
N1C2C1 & 87.32 & C2C1C4 & 87.59 & C4C1N4 & 87.76 & C4C1N4 & 87.48 \\
N1C4C1 & 87.34 & C2C1N1 & 86.55 & C1N4C3 & 92.79 & C1N4C3 & 93.04 \\
\hline Sum & 358.15 & & 358.49 & & 356.65 & & 356.12 \\
\hline
\end{tabular}

The first and second rows stand for the angles having mono and dinitro substituted atoms, respectively. Refer Figure 4 for the numbering of atoms.
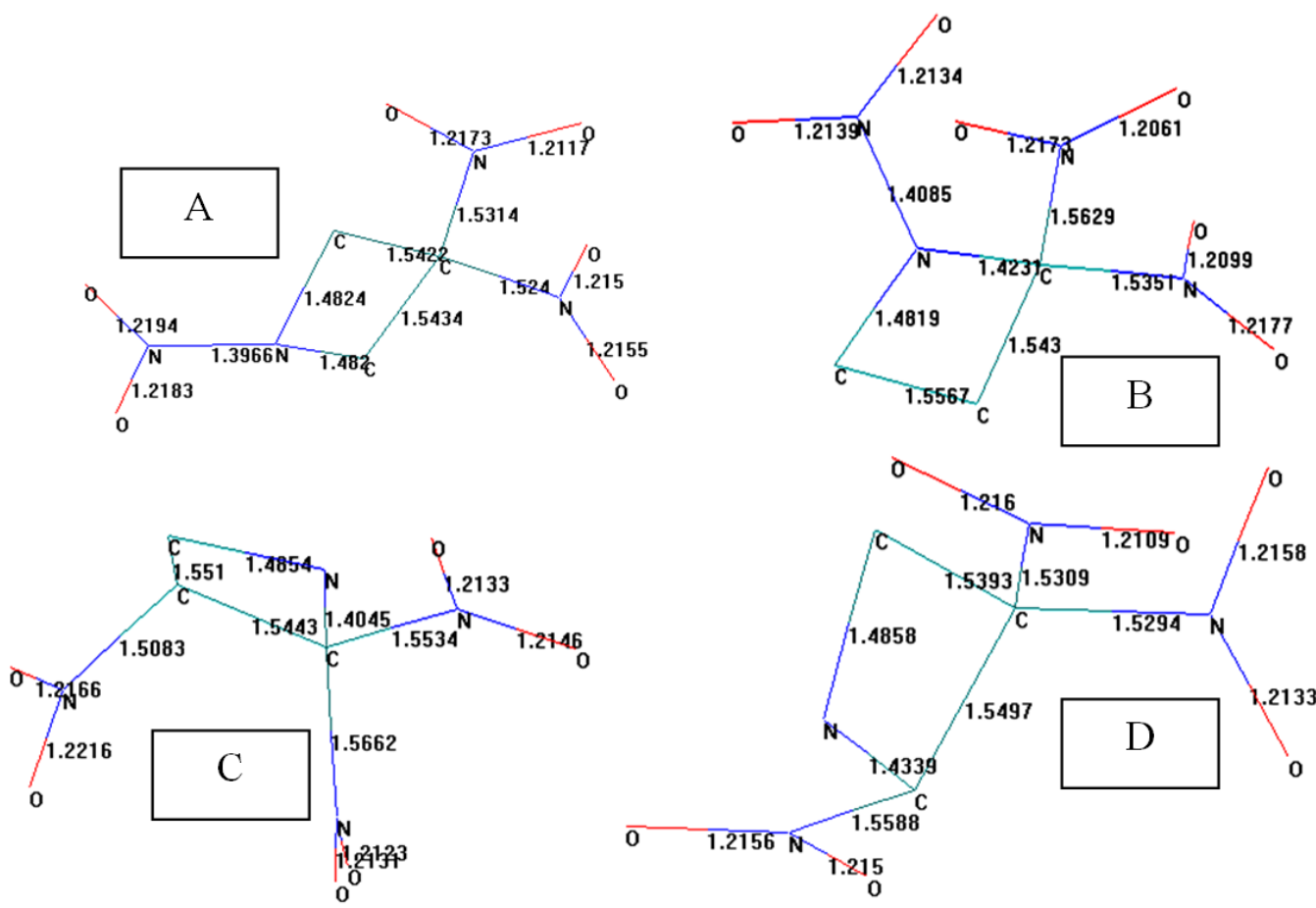

Figure 3. Calculated bond lengths of the isomers. 


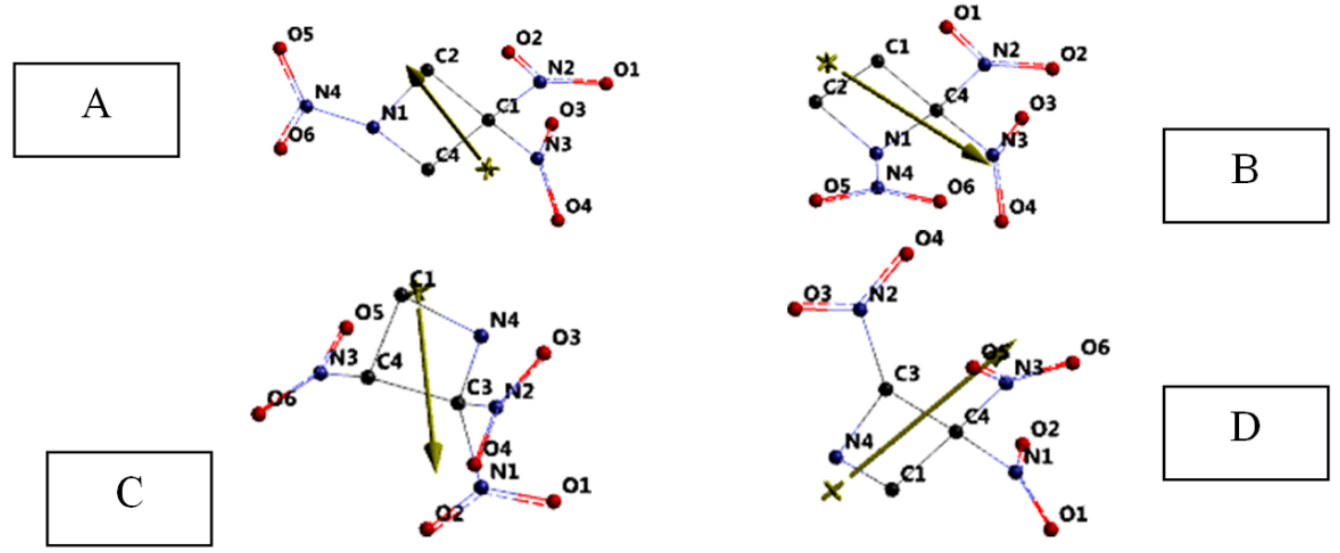

Figure 4. Numbering of atoms in the isomers.

Table 4 shows some energies of the isomers considered where E, ZPE and $\mathrm{E}_{\mathrm{C}}$ stand for the total electronic energy, zero point vibrational energy and the corrected total electronic energy, respectively. The data in the table indicate that electronic stability follows the order of $\mathrm{C}>\mathrm{D}>\mathrm{A}>\mathrm{B}$. Since structures of isomer-A and $-\mathrm{B}$ possess the nitramine group, then one may conclude that the presence of nitramine group destabilizes the trinitroazetidine system. Moreover, the presence of $\mathrm{C}-\mathrm{NO}_{2}$ groups on the vicinal position to the nitramine moiety (isomer-B) causes further destabilization compared to isomer-A.

Table 4. Some energies of the isomers.

\begin{tabular}{cccc}
\hline Structure & $\mathbf{E}$ & $\mathbf{Z P E}$ & $\mathbf{E}_{\mathbf{C}}$ \\
\hline A & -2066133.77 & 278.31 & -2065855.46 \\
B & -2066131.41 & 277.48 & -2065853.93 \\
C & -2066172.59 & 278.49 & -2065894.10 \\
D & -2066155.78 & 278.65 & -2065877.13 \\
\hline
\end{tabular}

Energies in $\mathrm{kJ} / \mathrm{mol}$.

Figure 5 shows the electrostatic potential (ESP) charges and maps of the systems considered. Note that the ESP charges are obtained by the program based on a numerical method that generates charges that reproduce the electrostatic potential field from the entire wavefunction [27]. As seen in the figure, except structure-A (TNAZ), the tip points 
of the dipole moment vectors are towards somewhere nearby the geminally nitrosubstituted side of the structures. On the other hand, an electrostatic potential map is a graph that shows the value of the electrostatic potential on an electron density isosurface corresponding to the van der Waals surface [28]. In the ESP map of structure-A the positive region almost surrounds the ring. Somewhat similar situation occurs in isomerD.
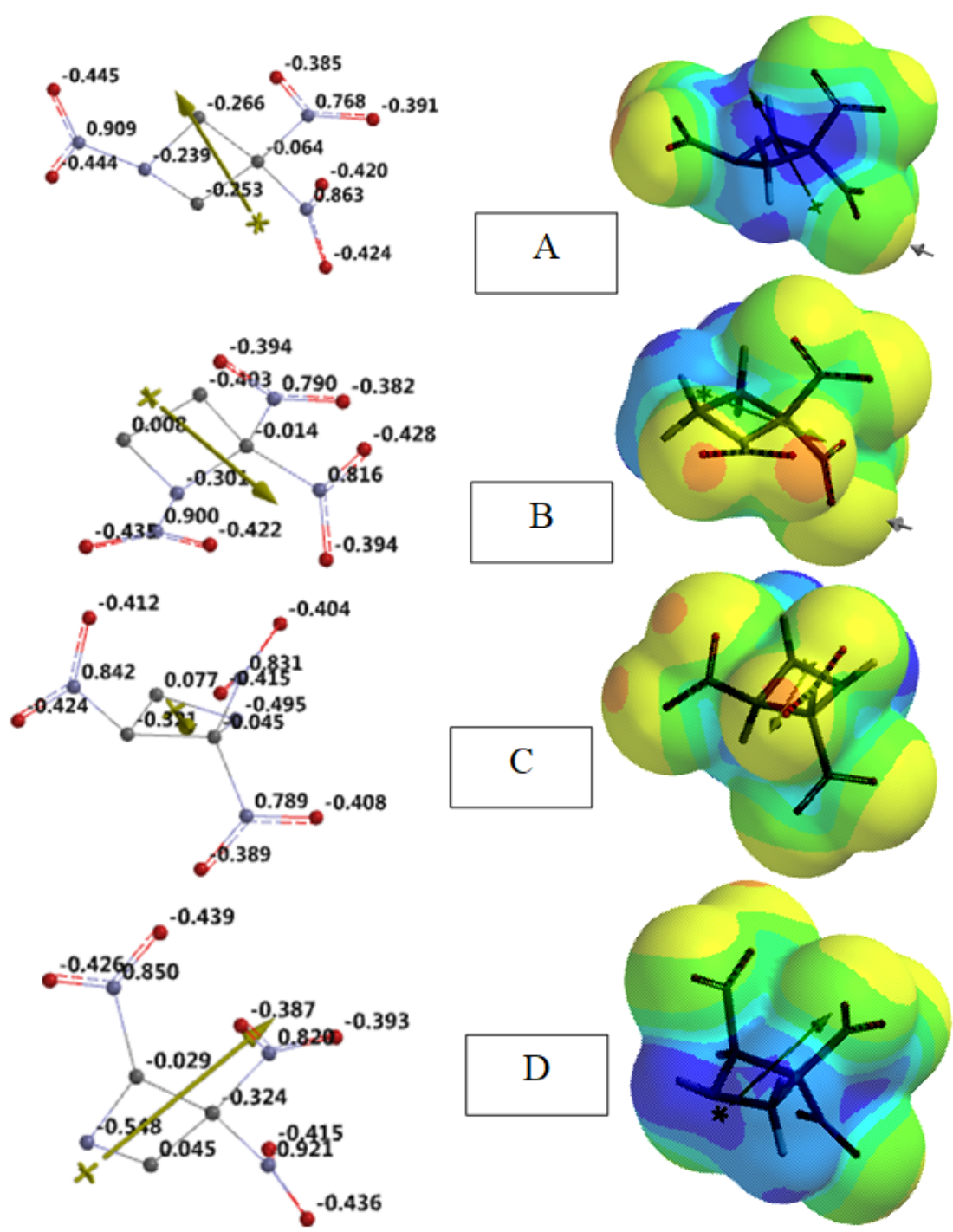

Figure 5. The ESP charges and maps of the isomers (Hydrogens not shown in the figures on the left hand side). 
Figure 6 shows some of the molecular orbital energy levels of the isomers. As seen in the figure, variations of position of the nitro groups affect not only the frontier molecular orbital energy levels but also greatly affect the energies of the inner-lying molecular orbitals. In isomer-A nearly degenerate LUMO and NEXTLUMO energies exist which is not the case in the others. In structures $\mathrm{C}$ and $\mathrm{D}$ the HOMO energy level raises up compared to others while the inner-lying molecular orbital energy levels shrink to exhibit more dense pattern. Note that in isomers $\mathrm{C}$ and $\mathrm{D}$ all three nitro groups are linked to carbon atoms thus the ring nitrogen holds its lone-pair electrons (no mesomeric effect exists). So, only $\sigma$-type effects (inductive effects) might be responsible for the energy rise of the molecular orbitals in $\mathrm{C}$ and $\mathrm{D}$ structures.
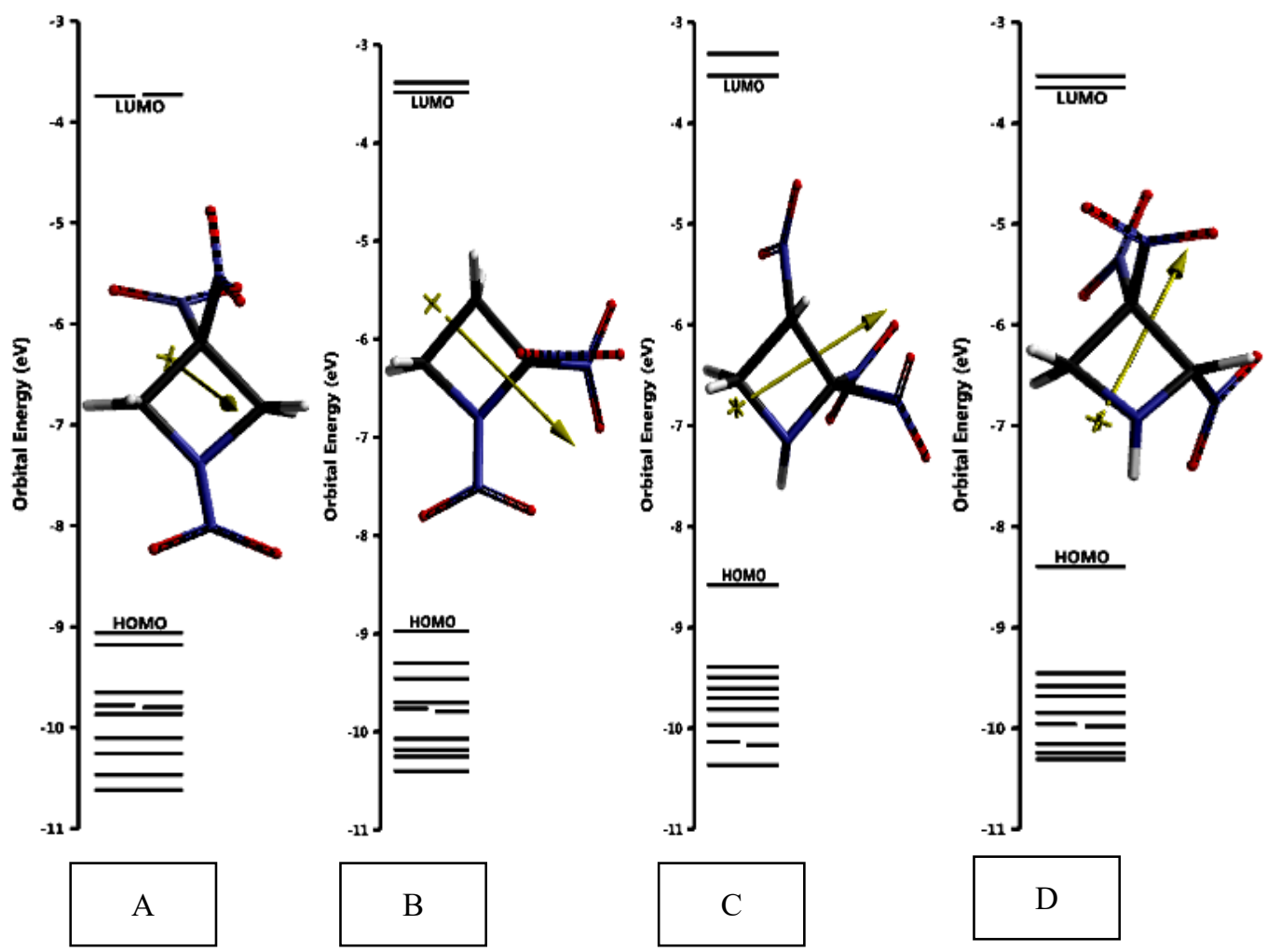

Figure 6. Some of the molecular orbital energy levels of the isomers.

Table 5 shows the HOMO, LUMO energies and the interfrontier molecular orbital energy gap, $\Delta \varepsilon,\left(\Delta \varepsilon=\varepsilon_{\mathrm{LUMO}}-\varepsilon_{\mathrm{HOMO}}\right)$ values of the isomers. The HOMO energy order is $\mathrm{A}<\mathrm{B}<\mathrm{C}<\mathrm{D}$ whereas the LUMO energies follow the order of $\mathrm{A}<\mathrm{D}<\mathrm{C}<\mathrm{B}$. Consequently, the interfrontier molecular orbital energy gap values fall in to the sequence of $B>A>C>D$. 
Table 5. The HOMO, LUMO energies and $\Delta \varepsilon$ values of the isomers.

\begin{tabular}{cccc}
\hline Structures & HOMO & LUMO & $\Delta \boldsymbol{\varepsilon}$ \\
\hline A & -874.55 & -361.35 & 513.20 \\
B & -866.14 & -336.18 & 529.96 \\
C & -827.92 & -340.60 & 487.32 \\
D & -810.51 & -352.00 & 458.51 \\
\hline
\end{tabular}

Energies in $\mathrm{kJ} / \mathrm{mol}$.

Note that the impact sensitivity of an explosive is related to $\Delta \varepsilon$ value such that decrease of it increases the sensitivity [29, 30]. Thus isomer-D should be the most sensitive one to impact stimulus, whereas isomer-B should be even less sensitive than structure-A (TNAZ). Nitro group is inductively and mesomerically electron withdrawing in character but obviously its mesomeric effect is more pronounced. In the case of a nitramine group, the lone-pair electrons of the amino nitrogen shifts towards the nitramine- $\mathrm{NO}_{2}$ group. This effect is most probably counter balanced by the inductive electron attracting effect of $\mathrm{C}-\mathrm{NO}_{2}$ groups.

On the other hand, hardness and electronegativity are defined as,

$$
\begin{gathered}
\text { Hardness }=-\left(\varepsilon_{\mathrm{HOMO}}-\varepsilon_{\mathrm{LUMO}}\right) / 2 \\
\text { Electronegativity }=-\left(\varepsilon_{\mathrm{HOMO}}+\varepsilon_{\mathrm{LUMO}}\right) / 2
\end{gathered}
$$

Table 6 shows hardness and electronegativity values of the isomers considered. The data in the table indicate that the order of hardness for these isomers is $B>A>C>D$, whereas the electronegativities follow the order of $A>B>C>D$.

Table 6. Hardness and electronegativity values of the isomers considered.

\begin{tabular}{ccc}
\hline & Hardness & Electronegativity \\
\hline A & 256.61 & 617.95 \\
B & 264.98 & 601.16 \\
C & 243.66 & 584.26 \\
D & 229.26 & 581.26 \\
\hline
\end{tabular}

Energies in $\mathrm{kJ} / \mathrm{mol}$. 
The calculated UV-VIS spectra (time-dependent DFT spectra) of the isomers considered are depicted in Figure 7. As seen in the figure all the isomers absorb in the UV region. The shoulder in the spectrum of B might arise from some subtle electronic effects involving the ring or through space effects among the nitro groups.
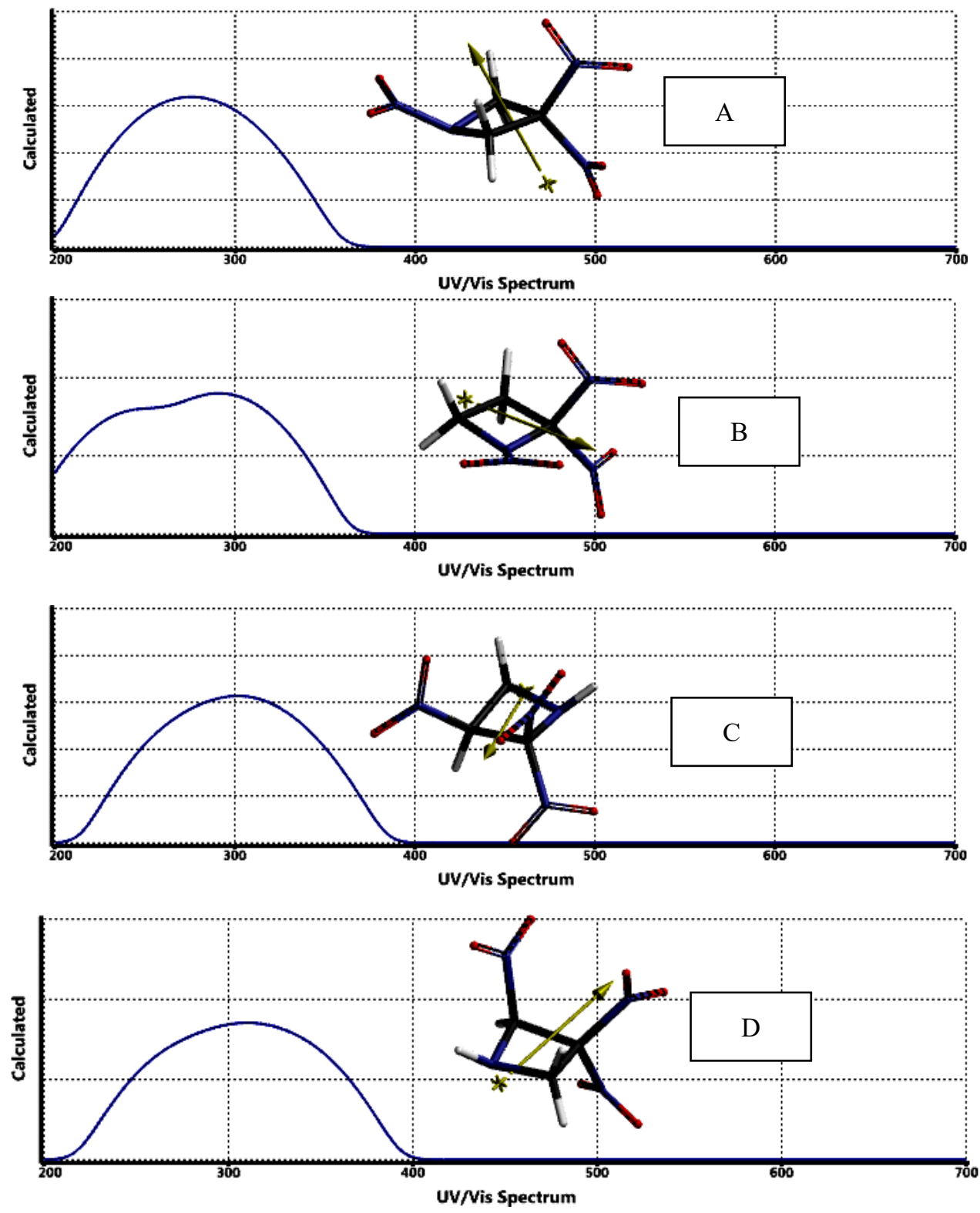

Figure 7. Calculated UV-VIS spectra of the isomers considered. 
Figure 8 shows the local ionization maps of the isomers. In the local ionization potential map, conventially red regions on the density surface indicate areas from which electron removal is relatively easy, meaning that they are subject to electrophilic attack. On the other hand, regions having blue color represent areas where ionization is relatively difficult.
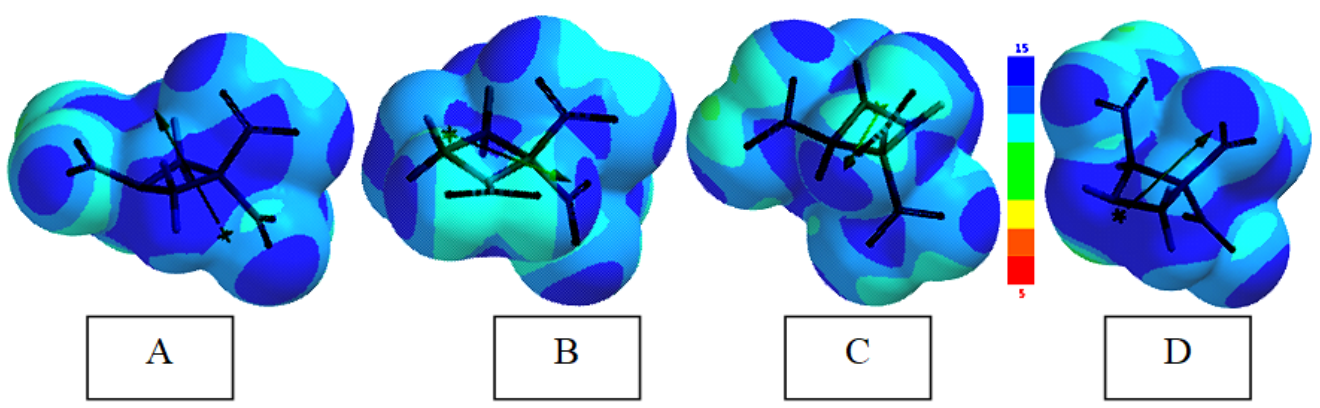

Figure 8. The local ionization maps of the isomers.

Figure 9 shows the LUMO maps of the isomers. A LUMO map displays the absolute value of the LUMO on the electron density surface. The blue color stands for the maximum value of the LUMO and the color red, the minimum value.

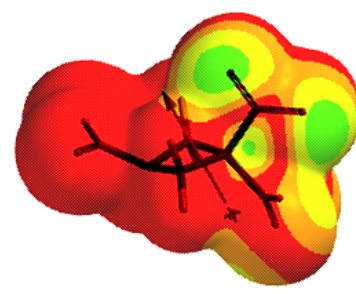

A

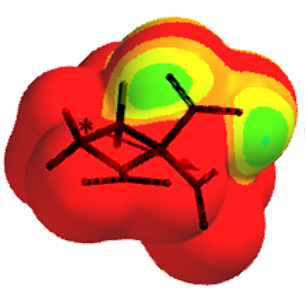

B

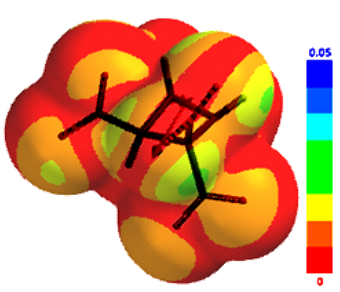

$\mathrm{C}$

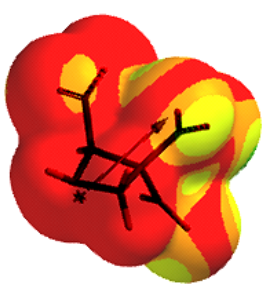

$\mathrm{D}$

Figure 9. The LUMO maps of the isomers.

\section{Conclusion}

The present density functional treatment considers four constitutional isomers of trinitroazetidine system. Two of them have nitramine moiety and the rest contain only C$\mathrm{NO}_{2}$ type bonds. All the isomers are electronically stable but endothermic structures. The nitramine type isomers are less stable and more endothermic than the others. One of the nitramine type isomers is electronically slightly less stable but more endothermic and less sensitive than TNAZ. 


\section{References}

[1] P.F. Pagoria, G.S. Lee, R.A. Mitchell and R.D Schmidt, A review of energetic materials synthesis, Thermochim. Acta 384 (2002), 187-204.

https://doi.org/10.1016/S0040-6031(01)00805-X

[2] H.S. Jadhav, M.B. Talawar, D.D. Dhavale, S.N. Asthana and V.V. Krishnamurthy, Alternate method to synthesis of 1,3,3-trinitroazetedine (TNAZ): Next generation melt castable high energy material, Indian J. Chem. Technol. 13 (2006), 41-46. http://nopr.niscair.res.in/handle/123456789/8455

[3] T.G. Archibald, R. Gilardi, K. Baum and C.J. George, Synthesis and x-ray crystal structure of 1,3,3-trinitroazetidine, J. Org. Chem. 55 (1990), 2920-2924. https://doi.org/10.1021/jo00296a066

[4] R.L. McKenney, Jr., T.G. Floyd, W.E. Stevens, T.G. Archibald, A.P. Marchand, G.V.M. Sharma and S.G. Bott, Synthesis and thermal properties of 1,3-dinitro-3(1',3'-dinitroazetidin-3'-yl) azetidine (TNDAZ) and its admixtures with 1,3,3trinitroazetidine (TNAZ), J. Energ. Mater. 16 (1998), 199-235.

https://doi.org/10.1080/07370659808217513

[5] A.M. Hiskey, M.C. Johnson and E.D. Chavez, Preparation of 1-substituted-3,3dinitroazetidines, J. Energ. Mater. 17 (1999), 233-252.

https://doi.org/10.1080/07370659908216106

[6] J. Zhang, R. Hu, C. Zhu, G. Feng and Q. Long, Thermal behavior of 1,3,3trinitroazetidine, Thermochim. Acta 298 (1997), 31-35.

https://doi.org/10.1016/S0040-6031(97)00056-7

[7] S. Zeman, The thermoanalytical study of some amino derivatives of 1,3,5trinitrobenzene, Thermochim. Acta 216 (1993), 157-168.

https://doi.org/10.1016/0040-6031(93)80389-R

[8] M. H. Keshavarz, Approximate prediction of melting point of nitramines, nitrate esters, nitrate salts and nitroaliphatics energetic compounds, J. Hazard. Mater. A 138 (2006), 448-451. https://doi.org/10.1016/j.jhazmat.2006.05.097

[9] Z. Jalovy, S. Zeman, M. Suceska, P. Vavra, K. Dudek and J.M. Rajic, 1,3,3Trinitroazetidine (TNAZ). Part I. Syntheses and properties, J. Energ. Mater. 19 (2001), 219-239. https://doi.org/10.1080/07370650108216127 
[10] D.S. Watt and M.D. Cliff, Evaluation of 1,3,3-trinitroazetidine (TNAZ) - A high performance melt-castable explosive, Technical Report DSTO-TR-1000, Defence Science and Technology Organization (DSTO), Aeronautical and Maritime Research Laboratory, Melbourne, Australia, 2000.

[11] A.K. Sikder and N. Sikder, A review of advanced high performance, insensitive and thermally stable energetic materials emerging for military and space applications, J. Hazard. Mater. A 112 (2004), 1-15. https://doi.org/10.1016/j.jhazmat.2004.04.003

[12] S. Iyer, E.Y. Sarah, M. Yoyee, R. Perz, J. Alster and D. Stoc, TNAZ based composition C-4 development, 11th Annual Working Group, Institute on Synthesis of High Density Materials (Proc.), Kiamesha Lakes, 1992.

[13] M. Oftadeh, M. Hamadanian, M. Radhoosh and M.H. Keshavarz, DFT molecular orbital calculations of initial step in decomposition pathways of TNAZ and some of its derivatives with $-\mathrm{F},-\mathrm{CN}$ and $-\mathrm{OCH} 3$ groups, Comput. Theor. Chem. 964 (2011), 262-268. https://doi.org/10.1016/j.comptc.2011.01.007

[14] J.O. Doali, R.A. Fifer, D.I. Kruzezynski and B.J. Nelson, The mobile combustion diagnostic fixture and its application to the study of propellant combustion Part-I. Investigation of the low pressure combustion of LOVA XM-39 Propellant, Technical Report No: BRLMR-3787/5, US Ballistic Research Laboratory, Maryland, 1989.

[15] J.P. Agrawal, Recent trends in high-energy materials, Prog. Energ. Combust. Sci. 24(1) (1998), 1-30. https://doi.org/10.1016/S0360-1285(97)00015-4

[16] M.D. Coburn, M.A. Hiskey and T.G. Archibald, Scale-up and wasteminimization of the Los Alamos process for 1,3,3-trinitroazetidine (TNAZ), Waste Management 17 (1997), 143-146. https://doi.org/10.1016/S0956-053X(97)10013-7

[17] L. Türker, Interaction of FOX-7 and TNAZ-A DFT Treatment, Exploratory Material Science Research 2(1) (2021), 1-9. https://dx.doi.org/10.47204/EMSR.2.1.2021.1-9

[18] L. Türker, A Composite of NTO and TNAZ-A DFT Treatment, Earthline Journal of Chemical Sciences 5(2) (2021), 261-274. https://doi.org/10.34198/ejcs.5221.261274 
[19] J.J.P. Stewart, Optimization of parameters for semi empirical methods I, $J$. Comput. Chem. 10 (1989), 209-220. https://doi.org/10.1002/jcc.540100208

[20] J.J.P. Stewart, Optimization of parameters for semi empirical methods II, J. Comput. Chem. 10 (1989), 221-264. https://doi.org/10.1002/jcc.540100209

[21] A.R. Leach, Molecular Modeling, Essex: Longman, 1997.

[22] W. Kohn and L.J. Sham, Self-consistent equations including exchange and correlation effects, Phys. Rev. 140 (1965), 1133-1138.

https://doi.org/10.1103/PhysRev.140.A1133

[23] R.G. Parr and W. Yang, Density Functional Theory of Atoms and Molecules, London: Oxford University Press, 1989.

[24] A.D. Becke, Density-functional exchange-energy approximation with correct asymptotic behavior, Phys. Rev. A 38 (1988), 3098-3100.

https://doi.org/10.1103/PhysRevA.38.3098

[25] S.H. Vosko, L. Wilk and M. Nusair, Accurate spin-dependent electron liquid correlation energies for local spin density calculations: a critical analysis, Can. J. Phys. 58 (1980), 1200-1211. https://doi.org/10.1139/p80-159

[26] C. Lee, W. Yang and R.G. Parr, Development of the Colle-Salvetti correlationenergy formula into a functional of the electron density, Phys. Rev. B 37 (1988), 785-789. https://doi.org/10.1103/PhysRevB.37.785

[27] SPARTAN 06, Wavefunction Inc., Irvine CA, USA, 2006.

[28] W.J. Hehre, A.J. Shusterman and W.W. Huang, A Laboratory Book of Computational Organic Chemistry, Irvine: Wavefunction,1998.

[29] V. Anbu, K.A. Vijayalakshmi, R. Karunathan, A.D. Stephen and P.V. Nidhin, Explosives properties of high energetic trinitrophenyl nitramide molecules: A DFT and AIM analysis, Arab. J. Chem. 12(5) (2019), 621-632. https://doi.org/10.1016/j.arabjc.2016.09.023

[30] N.R. Badders, C. Wei, A.A. Aldeeb, W.J. Rogers and M.S. Mannan, Predicting the impact sensitivities of polynitro compounds using quantum chemical descriptors, J. Energ. Mater. 24 (2006), 17-33. https://doi.org/10.1080/07370650500374326 